\title{
REBA: An Ergonomics Assessment for Machine Operator of Porang (Amorphophallus Muelleri)
}

\author{
Eko Nurmianto ${ }^{1}$, Arino Anzip ${ }^{2}$, and Dwi Endah Kusrini ${ }^{3}$ \\ ${ }^{1}$ Department of Systems and Industrial Engineering, Institut Teknologi Sepuluh Nopember, Surabaya \\ ${ }^{2}$ Department of Industrial Mechanical Engineering, Institut Teknologi Sepuluh Nopember, Surabaya \\ ${ }^{3}$ Department of Business Statistics, Institut Teknologi Sepuluh Nopember, Surabaya \\ e-mail: nurmi@ie.its.ac.id
}

\begin{abstract}
Abstrak-This Rapid Entire Body Assessment (REBA) has been applied for assessing operator of porang cutting machine in agriculture/forestry. An ergonomic team, industrial engineering, mechanical engineering, chemical engineering and business statisticians test the porang (amorphophallus muelleri) cutting machine and collect individually data more than 10 examples of postures to produce a new evaluation that combines dynamic and static posture loading factors, human load interfaces (couplings), and new limb concepts the assisted gravity. position. Initial reliability for inter-observer coding shows hope, but further work is needed to establish the trust for the machinery customer.
\end{abstract}

Keywords - REBA, postural analysis, manual handling, physical workload, ergonomics of appropriate technology, porang (amorphophallus muelleri).

\section{INTRODUCTION}

$\mathrm{P}$ REVIOUS research on the ergonomic design on appropriate technology has been carried out both for fishermen on the coast [1] and farmers in forest areas [2 4]. Ergonomics [5] in forestry areas have been implemented for example on ergonomic, mobile, and portable porang cutting and drying machines on motorbikes [6]. Trial of making a prototype cutting machine prototype needs an analysis of the work poster load when using the machine. Postural analysis can be a good technique for assessing work activities. The risk of musculoskeletal injury associated with recorded posture, in the context of workplace assessments and ergonomic work tools, can be a major factor for implementing change, so the availability of tasks in the field is very helpful for ergonomics practitioners. Most postural analysis techniques have a variety of uses but the results can be low in detail by Hignett [7]. Needs are felt in the spectrum of postural analysis tools, especially with sensitivity to unpredictable types of work postures found in activities in forests and other agricultural industries. This leads to the application of the following postural analysis tools: REBA (Rapid Entire Body Assessment) [7]. To test the inconvenience operators in the field can use REBA, RULA, or Body Part Discomfort Interview [8].

\section{OBJECTIVES}

The application of REBA aims to:
1. Application of a postural analysis system that is sensitive to musculoskeletal risk in a variety of porang cutting machine operation activities.

2. Dividing the body into individually encoded segments, with reference to the plane of motion.

3. Provides a rating system for muscle activity caused by static, dynamic, fast changing, or unstable postures.

4. Reflect the clutch which is important in handling the load but not always by hand.

5. Give the level of action with an indication of urgency.

6. Requires a minimum of pen and paper equipment.

7. Evaluate the workload of the porang cutting machine operator

\section{METHODOLOGY}

To evaluate the workload on the Porang cutter operator, the steps described below are to apply the REBA method by evaluating each member of the body equipped with illustrated pictures and simple tables on the Porang Cutting Machine and Dryer Operator, namely Operator (1) and Operators (2) (see figure 1).

\section{A. Group A: Assessment of limbs of the trunk, neck and legs}

The REBA method starts with assessing and giving individual scores to group A (trunk, neck and legs)

1) Scoring on the trunk

The first body member evaluated in group A is the trunk. This will be able to determine whether the worker is doing work with an upright position or not, and then determine the size of the flexion angle or extension of the body being observed and give a score based on trunk position, as Figure 2.

Scores on this body will increase, if there is a bending or twisting body position laterally (score +1$)$. Thus the score on this body must be modified according to the position that occurs, as illustrated in Figure 2 for the assessment on the Porang Machine Cut and Dryer Operators (1), the position of the body in a natural upright position (not forming flexion or extension). So, the score on the position of the body is 1 . Besides that, it does not bend or twist laterally. So, no additional score is needed. Thus, the score at such a body position is still worth $\mathbf{1}$. Whereas the assessment on the 


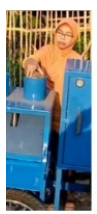

(a)

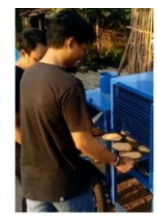

(b)

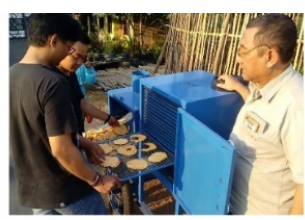

(c)

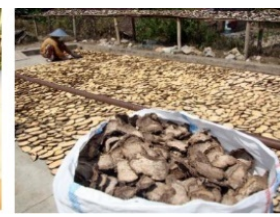

(d)

Figure 1. The work posture that was analyzed from the two operators of the cutting machine, operator 1 (figure a), operator 2 (figure b), the situation when cutting porang (amorphophallus muelleri) with a machine in a forest (c), the process of cutting and drying porang conventionally (d).

\begin{tabular}{lcl}
\hline \multicolumn{1}{c}{ Movement } & Score & Change Score \\
\hline Upright & 1 & \\
$0^{\circ}-20^{\circ}$ flexion & 2 & +1 if twisting or \\
$0^{\circ}-20^{\circ}$ extension & & $\begin{array}{l}\text { side flexed } \\
20^{\circ}-60^{\circ} \text { flexion }\end{array}$ \\
$>20^{\circ}$ extension & & \\
$>60^{\circ}$ flexion & 4 & \\
\hline
\end{tabular}

Figure 2. Scoring on the trunk.

\begin{tabular}{lcl}
\hline \multicolumn{1}{c}{ Movement } & Score & Change Score \\
\hline $0^{\circ}-20^{\circ}$ flexion & 1 & +1 if twisting \\
$0^{\circ}-20^{\circ}$ flexion or in & 2 & or side flexed \\
extension & & \\
\hline
\end{tabular}

Figure 3. Scoring on the neck.

\begin{tabular}{lcl}
\hline \multicolumn{1}{c}{ Position } & Score & \multicolumn{1}{c}{ Change Score } \\
\hline $\begin{array}{l}\text { Bilateral weight } \\
\text { bearing, walking }\end{array}$ & 1 & $\begin{array}{l}+1 \text { if knee(s) } \\
\text { between }\end{array}$ \\
or sitting & & \\
Unilateral & 2 & $\begin{array}{l}30^{\circ} \text { and } 60^{\circ} \\
\text { flexion } \\
\text { weight bearing }\end{array}$ \\
$\begin{array}{l}\text { Feather weight } \\
\text { bearing or an }\end{array}$ & & $>60^{\circ}$ flexion $(\mathrm{n} . \mathrm{b}$. \\
unstable posture & & Not for sitting) \\
\hline
\end{tabular}

Figure 4. Scoring on the legs.

Porang Cut Machine and Dryer Operator (2), the body position is in a natural upright position (not forming flexion or extension). So, the score on the position of the body is 1 . Besides that, it also does not bend or twist laterally. So, no additional score is needed. Thus, the score at such a body position is also still worth $\mathbf{1}$.

2) Scoring on the Neck

After completing assessing the body, the second step is to assess the position of the neck. The REBA method considers the possibility of two neck positions. The first position of the neck forms a flexion between $0-20^{\circ}$ and the second is the position of the neck bending Flexion or extension $>20^{\circ}$, as Figure 3.

The calculated score may be added if the worker's neck position is bent or twisted laterally, as illustrated in the Figure 3. As for the assessment on the Porang Cut Machine and Dryer Operator (1), the neck position is in a position not forming flexion or extension. So, the score on the position of the neck is 1 . However, due to the position of the neck
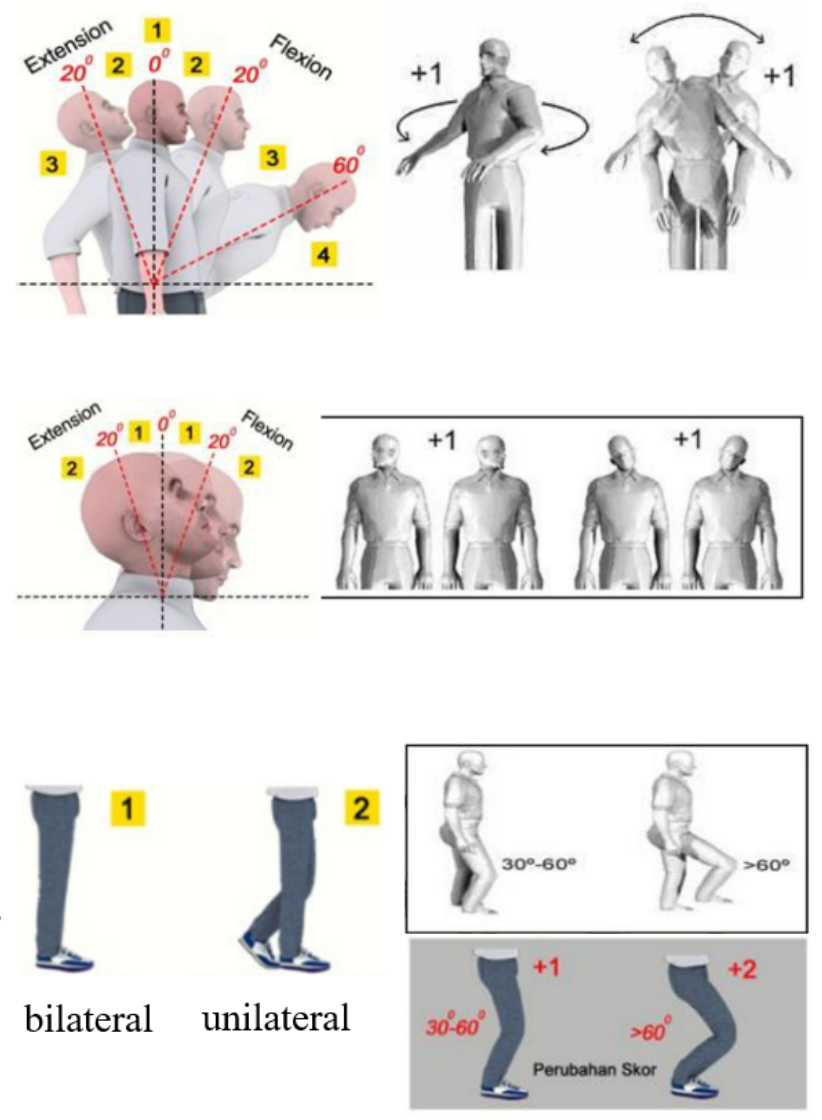

bending laterally, it is necessary to add a score of 1 . Thus, the score on the position of the neck becomes 2 . Whereas the assessment on the Porang Machine Cut and Dryer Operators (2), the position of the neck is in a position forming flexion $>20 \mathrm{o}$. So, the score on the neck position is 2. However, the operator's position does not bend or twist laterally. So, no additional score is needed. Thus, the score at the neck position like this is still worth $\mathbf{2}$.

3) Scoring on the Legs

The last part of scoring in group A is evaluating legs position. Initial assessment of the feet is to evaluate the distribution of body weight whether the position of the two legs is supported properly on the floor, both standing and walking. For more details, you can see in the pictogram.

The score on the legs will be added if one or both knees bend or form flexion. If one or both legs form a flexion between $30^{\circ}-60^{\circ}$, then the score on the legs is added 1 . If one or both legs form a flexion $>60^{\circ}$, then the score on the legs is added 2. For more details, you can see in Figure 4. 
2nd International Conference on Industrial and System Engineering (IConISE) and

7th Annual Conference on Industrial and System Engineering (ACISE) 2020

July $22^{\text {nd }}-23^{\text {rd }} 2020$, Surabaya, Indonesia

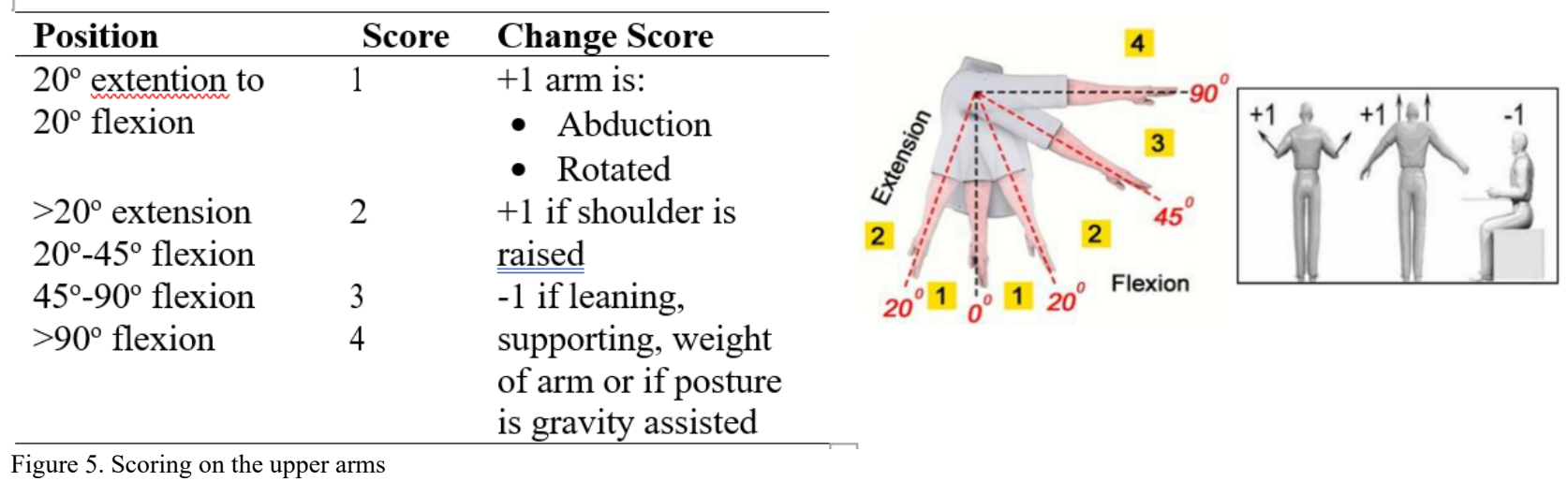

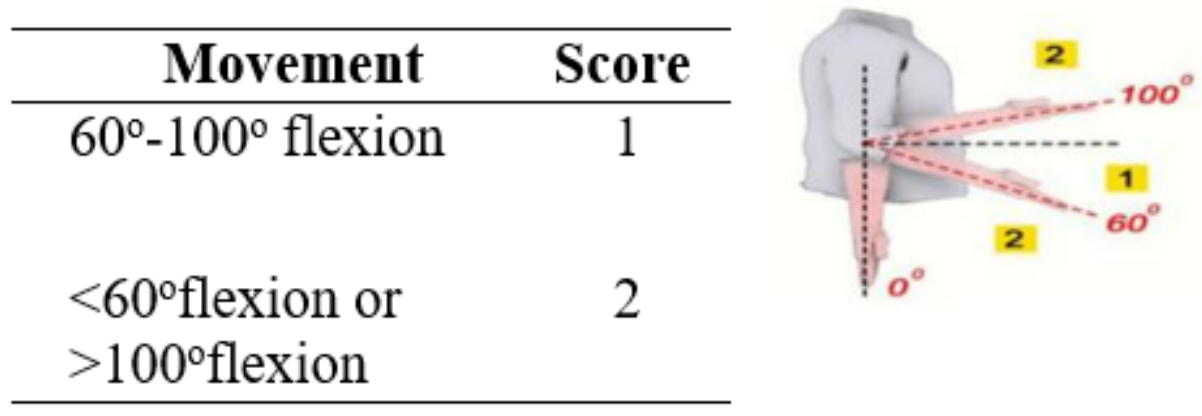

Figure 6. Scoring on the lower arms

\begin{tabular}{|c|c|c|}
\hline Movement & Score & Change Score \\
\hline $\begin{array}{l}0^{\circ}-15^{\circ} \text { flexion } / \\
\text { extention }\end{array}$ & 1 & $\begin{array}{l}+1 \text { if wrist } \\
\text { is deviated or }\end{array}$ \\
\hline $\begin{array}{l}>15^{\circ} \text { flexion/ } \\
\text { extension }\end{array}$ & 2 & twisted \\
\hline
\end{tabular}

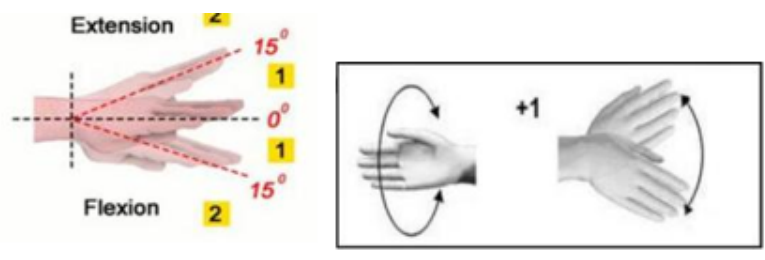

Figure 7. Scoring on the wrists

As for the assessment on the Cut and Dryer Machine Operators (1), the initial assessment of the position of the feet is in the position of both feet well supported on the floor in a standing state. So the score on the position of the legs is 1. Besides that, the position of the knee does not bend or form flexion, so no additional score is needed. Thus, the score on the position of the legs is still worth $\mathbf{1}$.

Whereas the assessment of the Porang Cut Machine and Dryer Operator (2), the initial assessment of the position of the feet is in the position of both feet well supported on the floor in a standing state. So the score on the position of the legs is 1 . In addition, the knee position does not bend or form flexion, so no additional score is needed. Thus, the score on the position of the legs is still worth 1 . The position of the legs on the Cut and Dryer Machine Operators (1) and (2) are in the same position.

\section{B. Scoring Group A: Assessment of the combination of} limbs, body parts, neck and legs.

Individual scores obtained from body, neck and leg positions will provide the first score for Table 1 is the application form for the REBA Method applied to Porang Machine Cut and Dryer Operators (1) and (2).
1) Scoring Group A on Cut and Dryer Machine Operators (1)

The score on the position of the trunk is worth $\mathbf{1}$, the score on the position of the neck is 2 , the score on the position of the legs is $\mathbf{1}$. Next is to combine in the form of Table 1 .

From the Table 1, it is found that the Group A Table Score is 1. After the Group A table score is known, the final Group A score is the result of adding the score in Table 1 with the addition score being adjusted according to the loading score in Table 2 the following.

Because the load carried by the Cut and Dryer Machine Operators (1) is less than $5 \mathrm{~kg}$, the Load Score on the Operator is 0 . So if added, the final Group A score on the Operator is still worth 1.

2) 2) Scoring Group A on Cut and Dryer Machine Operators (2)

The score on the position of the body is worth 1, the score on the position of the neck is worth 2 , the score on the position of the legs is worth 1 . Next is to combine in the form of Table 1 as previously described. So in the same way, the Group A Table score is 1.

It is known that the load carried by the Cut and Dryer Machine Operators (2) is not up to $5 \mathrm{~kg}$, then the Load Score 
Table 1.

Position of body, neck, and legs and load/force.

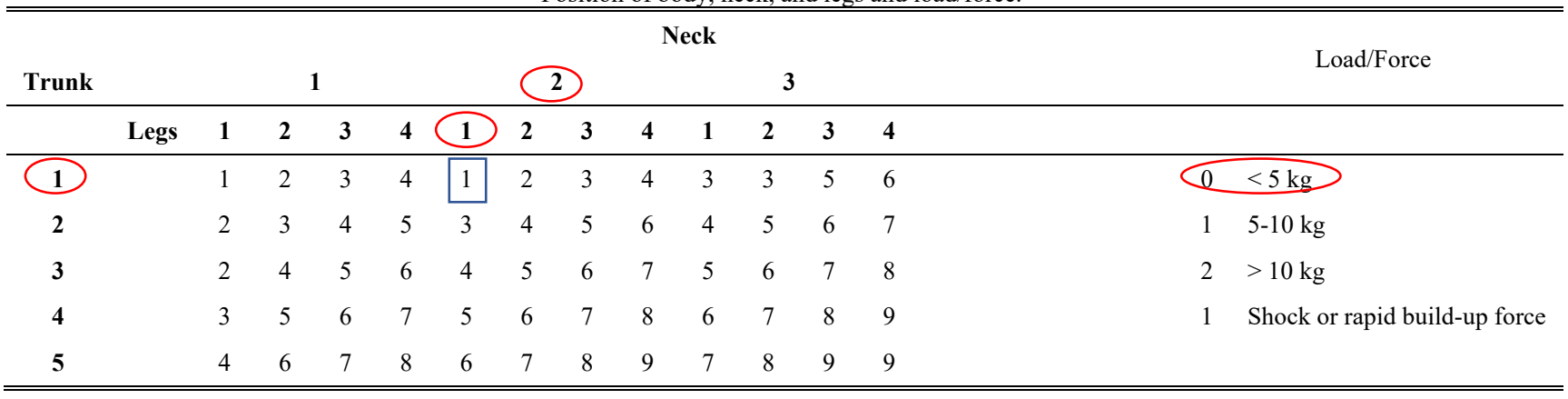

Tabel 2.

Assessment of a combination of upper limb, forearm and wrist; and the coupling.

\begin{tabular}{|c|c|c|c|c|c|c|c|}
\hline \multirow{3}{*}{ Upper arm } & & \multicolumn{6}{|c|}{ Lower arm } \\
\hline & \multirow[b]{2}{*}{ Wrist } & \multicolumn{3}{|c|}{ (1) } & \multicolumn{3}{|c|}{2} \\
\hline & & 1 & 2 & 3 & 1 & 2 & 3 \\
\hline 1 & & (1) & 2 & 2 & 1 & 2 & 3 \\
\hline 2 & & 1 & 2 & 3 & 2 & 3 & 4 \\
\hline (3) & & 2 & 4 & 5 & 4 & 5 & 5 \\
\hline 4 & & 4 & 5 & 5 & 5 & 6 & 7 \\
\hline 5 & & 6 & 7 & 8 & 7 & 8 & 8 \\
\hline 6 & & 7 & 8 & 8 & 8 & 9 & 9 \\
\hline
\end{tabular}

\begin{tabular}{llc}
\hline \hline & \multicolumn{1}{c}{ Coupling } & Score \\
\hline Good & Well-lifting handle and a mid-range, power grip & 0 \\
Fair & Hand hold acceptable but not ideal or coupling is acceptable via another part of & \\
& the body & 2 \\
Poor & Hand hold not acceptable although possible & 3 \\
Unacceptable & Awkward, unsafe grip, no handles & \\
& Coupling is unacceptable using other parts of the body & \\
\hline \hline
\end{tabular}

on the Operator is 0 . In the same way, if added, the final Group A score on the Operator is still valuable 1.

\section{Group B: Assessment of limbs and wrists.}

In the REBA method, the next assessment and grading is the individual score for group B (Arm and Wrist).

\section{1) Scoring on the Upper Arms}

The first limb that is evaluated in group B is the upper arm. This will be able to determine whether the worker is doing work with the arms and body positions forming the flexion or extension angle of the observed body and giving a score based on the position of the arm, see in Figure 5.

The score on the upper arm will increase, if there is a raised shoulder position, the arm rotated, and or if the arm is raised away from the body (score +1$)$. However, this upper arm score will be reduced by 1 if the arm is supported while working. Thus, the score on this upper arm must be modified according to the position that occurs, as illustrated by the Figure 4. As for the assessment on the Porang Cut Machine and Dryer Operator (1), the position of the upper arm with the body forms a flexion angle between $45^{\circ}-90^{\circ}$ so that the score is 3 , in addition it is in the shoulder position raised so that the score is added by 1 , but the position of the arm rests so that the score is reduced by 1 . Thus, the upper arm score becomes $3-1+1=3$. Whereas the evaluation on Porang Cut Machine and Dryer Operators (2), the position of the upper arm with the body forms an angle of flexion between $0^{\circ}-20^{\circ}$ so that the score is 1 , in addition to being in a shoulder position neither raised nor away from the body. Thus, the upper arm score remains valued at $\mathbf{1}$.

2) Scoring on the Lower Arms

After completing assessing the upper arm, the next step is to assess the position of the forearm. The REBA method considers the possibility of two forearm positions. The first position forms a flexion between $60^{\circ}-100^{\circ}$ and the second position forms Flexion $<60^{\circ}$ or flexion $>100^{\circ}$, as the Figure 6.

Unlike the assessment of other body parts, the score on the forearm is not added or decreased due to certain conditions. Good twist or certain other conditions. If the arm is in a twisted state, it is not included in the scoring of this part of the body, but rather it is included in the scoring of the wrist (the last part of group B scoring).

As for the assessment on the Porang Machine Cut and Dryer Operators (1), the position of the forearm with the body forms a flexion angle between $60 \mathrm{o}-100 \mathrm{o}$ so that the score is 1 .

Whereas the assessment on Porang Cut Machine and Dryer Operators (2), the position of the forearm with the body forms a flexion angle between $00-60$ o so that the score is 2 . 
2nd International Conference on Industrial and System Engineering (IConISE) and

7th Annual Conference on Industrial and System Engineering (ACISE) 2020

July $22^{\text {nd }}-23^{\text {rd }} 2020$, Surabaya, Indonesia

\section{3) Scoring on the Wrists}

The last part of scoring in group B is evaluating the position of the wrist. The REBA method considers the possibility of two wrist positions. The first position forms a flexion or extension between 0 o-15o and the second position forms a flexion or extension $<150$. For more details, you can see in the Figure 7.

The score on the wrist will be increased if the wrist at work experiences torque or deviation, both ulnar and radial. For more details can be seen in the Figure 7.

As for the assessment on the Porang Cut Machine and Dryer Operator (1), the initial assessment of the position of the wrist is in a position forming a flexion between $0 \mathrm{o}-15 \mathrm{o}$. So the score on the position of the wrist is 1. Besides that, the position of the wrist when working does not experience torsion or deviation, either ulnar or radial. Therefore, no additional scores are needed. Thus, the score on the position of the wrist is still worth 1 .

Whereas the evaluation on Porang Cut Machine and Dryer Operators (2), the initial assessment of the position of the wrist is in the position of forming an extension of more than 150 . So the score on the position of the wrist is 2 . In addition, the position of the wrist when working does not experience torsion or deviation, either ulnar or radial. Therefore, no additional scores are needed. Thus, the score on the position of the wrist is still worth 2 .

\section{Scoring Group B: Assessment of a combination of} upper limb, forearm and wrist.

Individual scores obtained from the Upper Arm, Forearm and Wrist will give the first score for Table 2 is the application form of the REBA Method applied to the Porang Machine Cut and Dryer Operators (1) and (2).

1) Scoring Group B on Cut and Dryer Machine Operators (1)

The score on the upper arm position is 3 , the score on the lower arm is 1 , the score on the wrist position is 1 . Next is to combine in the form of Table 2.

From the Table 2 scores are obtained as 3. After the Group B table scores are known, the final Group B score is the result of adding a score in Table 2 with a Grip or Coupling score where the addition is adjusted to the Coupling score in Table 2.

Due to the handle (holding porang) held by the Cut and Dryer Machine Operator (1) in the right grip position, right in the middle and firm grip, the Coupling Score on the Operator is 0. So if added, the final Group B score on the Operator is worth 3.

2) Scoring Group B on Cut and Dryer Machine Operators (2)

The score on the upper arm position is 1 , the score on the lower arm is 2 , the score on the wrist position is 2 . Next is to combine in the form of Table 2 as described earlier. So, in the same way, a Group B Table score of 2 is obtained.

It is known that the handle (holding porang) held by the Cutting Machine Operator and Porang Dryer (2) in the right grip position, right in the middle and strong grip, the
Coupling Score on the Operator is 0 . So, if added, the final Group B score on the Operator it is worth 2.

\section{E. Determination and Calculation of Final Score Table C}

Table 3 is the combined value of the final value of Group A and the final value of Group B. The final value of the Table 3 Score is the addition of the value of Table 3 with the score on the type of muscle activity.

1) Scoring Table 3 on Cut and Dryer Machine Operators (1)

The final score in Group A is 1, the final score in Group $B$ is 3. Next is to combine in the form of Table 3 .

From the Table 3, the Group C Table Score is obtained 1. After the Group C table's score is known, the final Group C score is the result of adding a score in Table 3 with a loading score where the addition is adjusted to the loading score in Table 3 .

Due to the type of activities carried out by Porang Cut and Dryer Machine Operators (1) not standing for a long time (standing static for more than 1 minute), and the time span of repetition of activities is not fast, and operator movements are not required to be fast (relaxed), the Score the type of activity on the Operator is 0 . So, if added, the final Group C score on the Operator is still worth 1.

2) Scoring Group C on Cut and Dryer Operators (2)

The score in Group A is 1, the final score in Group B is 2 . Next is to combine in the form of Table 3 as previously described. So in the same way, a Group C Table score of 1 is obtained.

It is known that the type of activities carried out by Porang Cut and Dryer Machine Operators (2) do not stand for a long time (standing static for more than 1 minute), and the time span of repetition of activities is not fast, and the operator's movements are not required to be fast (relaxed), then the score for the type of activity on the Operator is 0 . So if added, the final Group $\mathrm{C}$ score on that Operator is still worth 1 .

\section{DISCUSSION}

\section{A. Performance Standards Based on Final Scores}

This REBA method classifies the final score into 5 levels as shown in Table 4. Each level of Action determines the level of risk and suggested corrective actions in the position being evaluated. The greater the value of the results obtained, the greater the risk faced for the position in question. A value of 1 indicates a risk that can be ignored, while the maximum value is 15 , which states that the position is high risk and immediate action must be taken.

1) Assessment results on Operators (1)

Objective assessment based on individual score data used by the REBA method, obtained a value of "1", meaning that the work posture of Operator (1) Porang Cutting Machine has a risk level of "Can be ignored". So that the conclusions from the results of the assessment stated "unnecessary" changes to improve work attitude.

2) Assessment results on Operators (2)

Objective assessment based on individual score data used by the REBA method, obtained a value of "1", meaning that 
2nd International Conference on Industrial and System Engineering (IConISE) and

7 th Annual Conference on Industrial and System Engineering (ACISE) 2020

July $22^{\text {nd }}-23^{\text {rd }} 2020$, Surabaya, Indonesia

the Working Posture of Operator (2) Porang Cutting Machine has a "Negligible" risk level. So that the conclusions from the results of the assessment stated "unnecessary" changes to improve work attitude.

3) The application of the REBA

Method can be used as a guideline for evaluating work postures when operating porang cutting machines with a view to determining whether or not a corrective action is required in a particular work position. In addition, individual scores obtained in body segments, weights, grips, and muscle activity can help in solving ergonomic problems. So that prospective buyers of this cutting machine can trust more because the machine is ergonomic.

\section{ACKNOWLEDGMENTS}

Authors wishing to acknowledge that this research program was financially supported from Directorate General of Higher Education, Ministry of Technology Research and Higher Education, Republic of Indonesia.

\section{REFERENCES}

[1]. Otley D 1999 Performance management: A framework for management control systems research. Manag Account Res. 10(4) p 363-82.

[2]. Rusev SJ, Salonitis K 2016 Operational Excellence Assessment Framework for Manufacturing Companies. Procedia CIRP. 255:2727. doi.org/10.1016/j.procir.2016.08.026

[3]. Eka Rahayu Estuningsari, Nasir Widha Setyanto RYE 2013 PENGUKURAN KINERJA PERUSAHAAN BERBASIS KRITERIA PENILAIAN KINERJA UNGGUL ( KPKU ) BUMN ( Studi Kasus: Perum Jasa Tirta 1 Malang ) PERFORMANCE MEASUREMENT BASED COMPANY SUPERIOR PERFORMANCE CRITERIA ( KPKU ) BUMN ( Case study: Perum Jasa Tirta 1 Malang, , Univ Brawijaya. 2013;476-87.

[4]. Yongvanich K, Guthrie J 2006 An extended performance reporting framework for social and environmental accounting. Bus Strateg Environ. 15(5):309-21.

[5]. Gawankar SA, Kamble S, Raut R 2017 An investigation of the relationship between supply chain management practices (SCMP) on supply chain performance measurement (SCPM) of Indian retail chain using SEM. Benchmarking. Emerald 24(1):257-95. doi.org/10.1108/bij-12-2015-0123

[6]. Neely A, Gregory M, Platts K 2005 Performance measurement system design: A literature review and research agenda. Int J Oper Prod Manag. 25(12):1228-63.

[7]. Tools JM 2017 SWOT ANALYSIS: A THEORETICAL REVIEW. 7(1):45-56. Available from: https:/www.researchgate.net/publication/319367788_SWOT_ANA LYSIS_A_THEORETICAL_REVIEW.

[8]. Nurmianto E, Ciptomulyono U, Suparno, Kromodihardjo S 2015 Manual Handling Problem Identification in Mining Industry: An Ergonomic Perspective. Procedia Manuf. Elsevier BV. 4 p 89-97. doi.org/10.1016/j.promfg.2015.11.018 